\title{
Aerodynamic Analysis of a Supersonic Transport Aircraft at Landing Speed Conditions
}

\author{
Andrea Aprovitola, Pasquale Emanuele Di Nuzzo, Giuseppe Pezzella * (D) and Antonio Viviani
}

check for updates

Citation: Aprovitola, A.; Di Nuzzo, P.E.; Pezzella, G.; Viviani, A. Aerodynamic Analysis of a Supersonic Transport Aircraft at Landing Speed Conditions. Energies 2021, 14, 6615. https://doi.org/ $10.3390 /$ en14206615

Academic Editor: Antonio Crespo

Received: 26 July 2021

Accepted: 8 October 2021

Published: 13 October 2021

Publisher's Note: MDPI stays neutral with regard to jurisdictional claims in published maps and institutional affiliations.

Copyright: (c) 2021 by the authors. Licensee MDPI, Basel, Switzerland. This article is an open access article distributed under the terms and conditions of the Creative Commons Attribution (CC BY) license (https:/ / creativecommons.org/licenses/by/ $4.0 /)$.
Engineering Department, Università della Campania “L.Vanvitelli”, Via Roma 29, I-81031 Aversa, Italy; andrea.aprovitola@unicampania.it (A.A.); pasqualeemanuele.dinuzzo@studenti.unicampania.it (P.E.D.N.); antonio.viviani@unicampania.it (A.V.)

* Correspondence: giuseppe.pezzella@unicampania.it

Abstract: Supersonic flight for commercial aviation is gaining a renewed interest, especially for business aviation, which demands the reduction of flight times for transcontinental routes. So far, the promise of civil supersonic flight has only been afforded by the Concorde and Tupolev T-144 aircraft. However, little or nothing can be found about the aerodynamics of these aeroshapes, the knowledge of which is extremely interesting to obtain before the development of the next-generation high-speed aircraft. Therefore, the present research effort aimed at filling in the lack of data on a Concordelike aeroshape by focusing on evaluating the aerodynamics of a complete aircraft configuration under low-speed conditions, close to those of the approach and landing phase. In this framework, the present paper focuses on the CFD study of the longitudinal aerodynamics of a Concorde-like, tailless, delta-ogee wing seamlessly integrated onto a Sears-Haack body fuselage, suitable for civil transportation. The drag polar at a Mach number equal to 0.24 at a $30 \mathrm{~m}$ altitude was computed for a wide range of angles of attack $\left(0^{\circ}, 60^{\circ}\right)$, with a steady RANS simulation to provide the feedback of the aerodynamic behaviour post breakdown, useful for a preliminary design. The vortex-lift contribution to the aerodynamic coefficients was accounted for in the longitudinal flight condition. The results were in agreement with the analytical theory of the delta-wing. Flowfield sensitivity to the angle of attack at near-stall and post-stall flight attitudes confirmed the literature results. Furthermore, the longitudinal static stability was addressed. The CFD simulation also evidenced a static instability condition arising for $15^{\circ} \leq \alpha \leq 20^{\circ}$ due to vortex breakdown, which was accounted for.

Keywords: supersonic aircraft; SST vehicle; aerodynamics; landing aerodynamics; delta-wing CFD; vortex-lift

\section{Introduction}

High-speed flight represents the next frontier of passenger transportation as it allows a remarkable flight time reduction, especially on long-range intercontinental routes. Supersonic aircraft (SA), in fact, operate at a cruise speed significantly higher compared to conventional transonic aircraft. As expected, this is particularly attractive for business customers as it improves passenger comfort and business. However, flying beyond the sound barrier is currently only performed by military aircraft. This is true, except for a few decades in the past, where the Concorde and Tupolev Tu-144 allowed supersonic civilian transport.

Up to now, the Concorde and Tu-144 aircraft represented the only answer to the worldwide high-speed aviation need. For instance, Concorde was designed to fly at twice the speed of sound, exactly at $M_{\infty}=2.04$ (i.e., $2180 \mathrm{~km} / \mathrm{h}$ ), and at a cruise altitude of about $18.3 \mathrm{~km}$, while seating from 92 to 128 passengers. It had the first flight in 1969 and started commercial operations from 1976 until 2003, when it was retired due to apparent safety concerns [1]. Concorde was perceived by people as the right answer of aerospace science and technology, which allowed men to land on the Moon in 1969, to the need to link, as fast as possible, two very distant points all over the world. 
Forty-five years have now passed since the Concorde performed its first-ever commercial flight. This is a very long time on the scene of airline transportation. Fortunately, even if some environmental issues of SA (e.g., sonic booms, noise emissions, and pollution) are not yet fixed, today a renewed interest in commercial high-speed flight is maturing. Examples of flight time reductions for supersonic cruises are summarized in Table 1, where a flight time for $M_{\infty}=0.9$, representative of conventional transonic flight, is also reported for [1].

Table 1. Example of flight time reductions due to supersonic cruise (cruise speed is assumed for the full route). From [1].

\begin{tabular}{lccccc}
\hline Origin & Destination & Range $(\mathbf{n m})$ & Mach $\mathbf{0 . 9}$ & Mach 1.4 & Mach 2.2 \\
\hline New York (JFK) & Los Angeles (LAX) & 2200 & $3.7 \mathrm{~h}$ & $2.4 \mathrm{~h}$ & $1.5 \mathrm{~h}$ \\
New York (JFK) & London (LHR) & 3000 & $5.0 \mathrm{~h}$ & $3.2 \mathrm{~h}$ & $2.1 \mathrm{~h}$ \\
Los Angeles (LAX) & Bejiing (PEK) & 5400 & $9.1 \mathrm{~h}$ & $5.6 \mathrm{~h}$ & $3.7 \mathrm{~h}$ \\
\hline
\end{tabular}

Designing an SA demands a huge effort to overcome all the issues related to the extremely challenging flight conditions, e.g., high-speed aerodynamics, aeroheating, stability, propulsion, structures, materials, low-speed aerodynamics, etc. For instance, during cruise, SA face a high-speed flow regime for the wider flight phase. Therefore, particular care is given in designing an aircraft aeroshape with a needle-like fuselage, low-aspect-ratio (AR) wing, and sharp leading edges for the wing and vertical tail in order to limit the wave drag penalty, which is uppermost at supersonic speeds.

Cruise flight, however, even if the wider phase of flight, does not represent the only concern of designers. Landing on a runway, in fact, eventually demands good aerodynamics also at subsonic speeds, where a low AR wing is detrimental for the needed low-speed aerodynamic performance. Fortunately, these requirements are just apparently antithetical if a low AR delta-wing (DW) (i.e., slender delta) design solution is adopted for the aircraft. As is well known, in fact, DW aerodynamics is characterised by the vortex-lift phenomenon, which is able to provide consistent lift contribution at rather high angles of attack (AoAs).

The aerodynamics of DW with different aspect ratios is widely discussed in the literature by means of analytical, computational fluid dynamics (CFD), and wind tunnel investigations [2-7]. However, very little or nothing can be found about the aerodynamic data of delta-winged aeroshapes with a fuselage or even with a fuselage and tail. This is especially true for the Concorde aeroshape, which having already flown, is extremely interesting to investigate envisioning the development of next-generation high-speed aircraft. Therefore, the present research effort aimed at filling in the lack of data of a Concorde-like aircraft. Attention was focused on the aerodynamic appraisal of a complete aircraft configuration under low-speed flight conditions, close to a runway approach and landing. The investigations were performed with fully turbulent, three-dimensional CFD simulations carried out at several AoAs. In particular, this research effort focused on the longitudinal steady-state aerodynamic performances and static stability appraisal, at verylow-speed conditions of a fully representative supersonic aircraft configuration for civil transportation.

In the landing phase, delta-winged aircraft attain a very high AoA, larger than that of conventional transonic aircraft. Therefore, this flight condition can be very critical, especially from the aerodynamic point of view. At such high attitudes, slender DWs experience sudden changes of aerodynamic loading due to conical flow disruption over the leading edge (vortex breakdown) [8]. Further (undesired) increments of the AoA eventually create nonlinear effects with a large value of the stability derivatives, causing dynamic stability issues [8]. Therefore, in view of a reintroduction of civil SA, it is important for preliminary design purposes to gain a fast and accurate response on the global aerodynamics in a range of AoAs up and past the vortex breakdown condition. The drag polar up to 
$60^{\circ} \mathrm{AoA}$ and for $M_{\infty}=0.24$ in longitudinal flight conditions was evaluated with steady, three-dimensional, and fully turbulent CFD simulations.

Considering the computational overhead of a CFD simulation performed on a complete aircraft configuration using an unsteady methodology such as large eddy simulation (LES) or detached eddy simulation (DES), a steady Reynolds-averaged Navier-Stokes (RANS) approach was considered in the present study. Although all unsteady effects caused by vorticity interaction with aircraft surfaces are averaged out, steady RANS simulations represent a good tradeoff to not limit the current study to specified values of the AoA. Moreover, RANS simulations allow fast computations (of a half-day order of magnitude) to consider a wider interval of flight incidences up to and post the breakdown AoA. The vortex-lift contribution to aerodynamic coefficients is accounted for, and flowfield sensitivity to AoA is addressed.

The paper is organised as follows. Section 2 deals with currently ongoing projects dealing with SA and with the principal associated design issues. In Section 3, a detailed resume of related research to DW technology at low-speed and landing AoA is addressed. Then, Section 4 deals with the instability phenomena driving to flow breakdown on the DW.

Finally, in Section 5, the results of several CFD simulations are provided and discussed in detail. Vorticity and pressure distributions are evaluated at near-to-stall and poststall AoA, and their influence on the global aerodynamic coefficients is accounted for, by comparison with analytical DW theory. Although flow unsteadiness associated with breakdown was not considered here, a preliminary evaluation to investigate the effect of breakdown on the global aerodynamic coefficient was performed.

\section{Overview on Supersonic Aircraft under Development and Investigation}

Since the retirement of Concorde, attention to civilian supersonic flight has been lacking for about two decades. Currently, however, some U.S. companies are showing renewed interest in supersonic transport (SST) for both business and common routes, due to the availability of a higher technology readiness level (TRL) than in the past [1,9]. Further, aviation analysts consider the business jet market the driving force for the rebirth of supersonic flight. Figure 1 shows the SA concepts, namely AS2, S-512, and Overture, under development by Aerion, Spike Aerospace, and Boom aircraft factories, respectively [10-12].

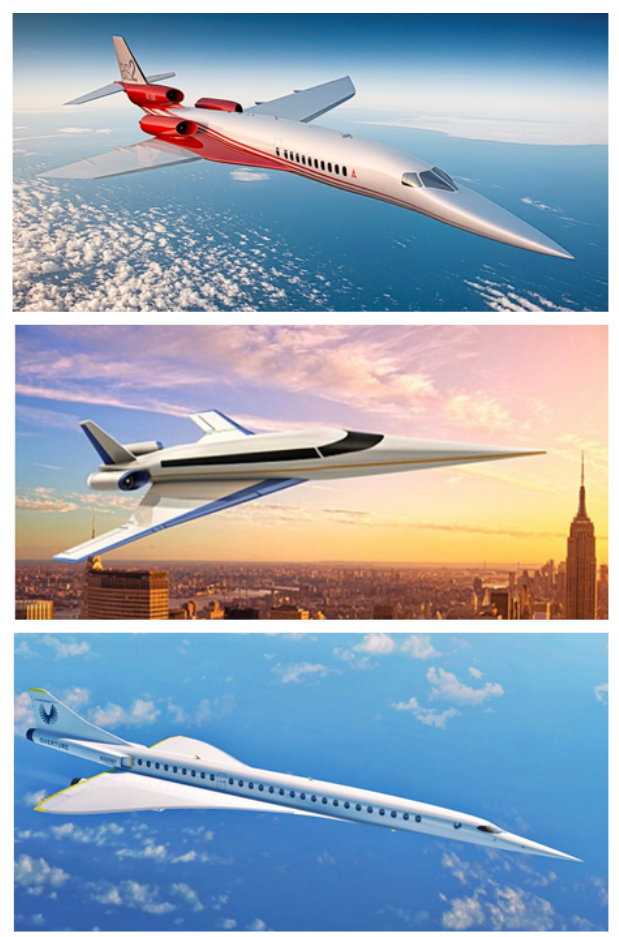

Figure 1. Aerion AS2, Spike S-512, and Boom Overture aircraft. From [10-12]. 
AS2 and S-512 are two business jets, while Overture is a commercial high-speed civil transport (HSCT) aircraft. The Aerion concept AS2 is designed to carry 12 passengers with a cruise speed of $M_{\infty}=1.4$ and a range of $4700 \mathrm{~nm}$ [10]. Spike S-512 features a cruise speed of $M_{\infty}=1.6$, a range of $6200 \mathrm{~nm}$, and 18 passengers [11]. Finally, Overture is a Mach 2.2 HSCT airliner with 55 passengers, a range of $4500 \mathrm{~nm}$, and a cruise altitude of about $60,000 \mathrm{ft}[1,12]$. Such a high altitude is needed because of the high-speed cruise results in both high mechanical (pressure) and thermal (skin-friction) stresses. Therefore, in order to mitigate these stresses, lower air density is mandatory. Recall that a speed of about $M_{\infty}=2$ allows using aluminium. Above this speed, the friction with the air (i.e., aerodynamic heating) warms up the SA so much that a high-temperature alloy (aluminium begins to soften) or a thermal protection system must be used. Considering the present civil aviation routes, Overture can fly from almost any United States (e.g., New York to Paris or Dallas to London) destination to Europe. However, it requires refuelling to reach Asian destinations [1].

All the above concepts are expected to perform commercial service in the middle of this decade, except AS2, which seems to have an uncertain future.

In this framework, aerospace factories and research centres are also involved in designing flying test beds for in-flight investigations in order to increase the TRL of supersonic flight [13]. For instance, consistent research efforts are currently focused on low-boom flight demonstration (LBFD) missions, which actually explore new improved technologies and their implementation on next-generation SA [9]. Recall that the sonic boom is still the main design concern for commercial SA due to the prohibition on supersonic overland flight [1]. In 2015, NASA started LBFD research investigations, which included the design of a quiet supersonic transport (QueSST) aircraft, namely the X-59 [14]. This X-plane has a cruise Mach number of 1.4 and a sonic boom perceived below 75 decibels (PLdB). Thanks to the experience on the X-59, in June 2019, Lockheed Martin provided the design of a quiet supersonic airliner (QSTA) consisting of a twin-engine aircraft able to carry 40 passengers at $M_{\infty}=1.8$. Research activities highlight that particular care must be taken in designing aircraft configurations, especially in opportunely shaping the front fuselage, wing, and their integration to allow boomless cruise, i.e., to reduce the aeroplane sonic boom signature to a reasonable noise footprint standard [15-17]. According to the Whitham theory, in fact, the entity of the overpressure signature to the ground depends onto the wave drag due to the volume and the wave drag due to lift $[18,19]$.

\section{Research Framework and Background}

The aerodynamics of DW aeroshapes has been extensively studied in the literature both for sharp and blunt leading edges. Delta-winged aircraft, in fact, show a different aerodynamic behaviour when compared to the conventional low-sweep angle or straight wing planforms. At an AoA between about $10^{\circ}$ and $30^{\circ}$, the DW geometry (i.e., high sweep angle and sharp leading edge radii) promotes the creation of two conical vortices at the wing leeside. These leading edge vortices globally create an additional lift contribution referred to as vortex-lift (VL).

Ghaffari et al. [20] performed one of the first RANS simulations on a real delta-winged aircraft at a high AoA. In order to understand the structure and formation of the leading edge vortices, the flow features on a F-18 high alpha research vehicle (HARV) at $M_{\infty}=0.34$, $\alpha=19^{\circ}$ were considered. Several grid resolution studies were performed in order to control the dissipative component of the local truncation error over the leading edge vortex resolution. With increased computational power, research focused on the unsteady effects of a DW associated with vortex breakdown [3-7]. The breakdown is created by the shearlayer instabilities, which are responsible for the vortex bursting [21]. As the AoA of a DW increases, the leading edge vortex experiences a sudden axial deceleration inside the primary core. By increasing the AoA, the vorticity expands in the cross-sectional plane and eventually affects the quality of the control effectiveness, producing severe buffeting phenomena [22]. 
Gursul et al. [7] explored the sensitivity to the leading edge radius of the flow separation and of the attachment location for a nonslender DW. A rounded leading edge delta-wing exhibited a dual vortex primary structure and, for any given AoA, a stall delay. Extensive experimental investigations were performed by Breitsamer [22] to assess the unsteady effects of breakdown over the turbulent flow that develops over a DW in near- and post-stall incidence. The instability of the breakdown at a high AoA was correlated to unsteady low-frequency pressure waves and to increased turbulent fluctuations. Cummings et al. [23] adopted several methodologies (RANS, DES, and DDES) to study the dual-vortex topology on a VFE-2 delta-wing with a variable leading edge radius. The accuracy of the DDES model showed that the dual-vortex system was created by the presence of a rounded leading edge. However, DDES models require computing resources not affordable for design applications. Jian et al. [24] developed a numerical method based a moving mesh method and DDES. The unsteady vortex breakdown of a DW subjected to a pitching motion was modelled using an adaptive dissipation in the matching between the LES and RANS interface. The burst point and dynamic pitching stability were found to be closely related to the wing buffeting. Hybrid RANS-LES studies on a DW at a low subsonic Mach number were also performed in Zhou et al. [25]. The open-source code SU2 was used to analyse the quality of the grid resolution for the vortex breakdown phenomenon. The authors found that adaptive mesh refinement could be adopted to overcome the nonphysical time delay, due to the RANS-LES transition region. The literature study showed that except for a few cases, researchers have focused on the unsteady characteristics only of a delta-wing-shaped planform (rather than focusing on the whole aircraft configuration) at high AoAs. This aspect has been performed with high-accuracy CFD LES/U-RANS methods able to describe nonlinear dynamic instability phenomena at breakdown or through experimental observations. However, in all the above-mentioned works, a Concorde-like configuration at high AoAs and very low-Mach numbers seems not to have been extensively studied. Therefore, although the present study does not describe unsteady phenomena, the CFD of a complete aircraft allows useful highly accurate (nonengineering level) assessment of the breakdown effect on the aerodynamic performances. This study also demonstrates the suitability of RANS computations in a preliminary design loop to obtain the aircraft's static margin.

\section{Aerodynamics of a Delta-Winged Aircraft}

Delta-winged aeroshapes are common for SA. The aerodynamics of such configurations, in fact, presents interesting figures of merit for both subsonic and supersonic regimes. For instance, at supersonic speeds, the high sweep angle, $\Lambda$, of the DW allows limiting the drag increase by increasing the critical Mach number with respect to a classical straight-wing at the same AoA. As is well known, in fact, the drag at supersonic speeds is strongly related to the wingspan. Additionally, delta planforms improve the longitudinal stability by reducing the displacement of the aerodynamic centre toward the tail, which takes place during the acceleration to supersonic speeds.

As far as subsonic speed is concerned, delta-winged aircraft are characterized by the VL phenomenon. This lift contribution is so important that several aircraft configurations also feature highly swept lifting surfaces in front of the wing, called wing strakes [26].

\subsection{Vortex-Lift Phenomenon}

According to small disturbance assumptions, the aerodynamics of the DW was modelled by the slender wing theory (SWT) [27]. It accurately expresses the lift coefficient $\left(C_{L}\right)$ as a function of the AoA, $\alpha$, and wing $A R$ :

$$
C_{L}=\frac{\pi A R}{2} \alpha
$$

Equation (1) indicates that a lower $A R$ results in a lower lift coefficient at a low speed, thus leading to extremely long take-off runs and high landing speeds. 
Fortunately, highly sweptback delta wings are able to produce strong vortices on their leeside, which lower the air pressure there and cause lift to be greatly increased when flying at high AoAs (i.e., take-off and landing); see Figure 2.

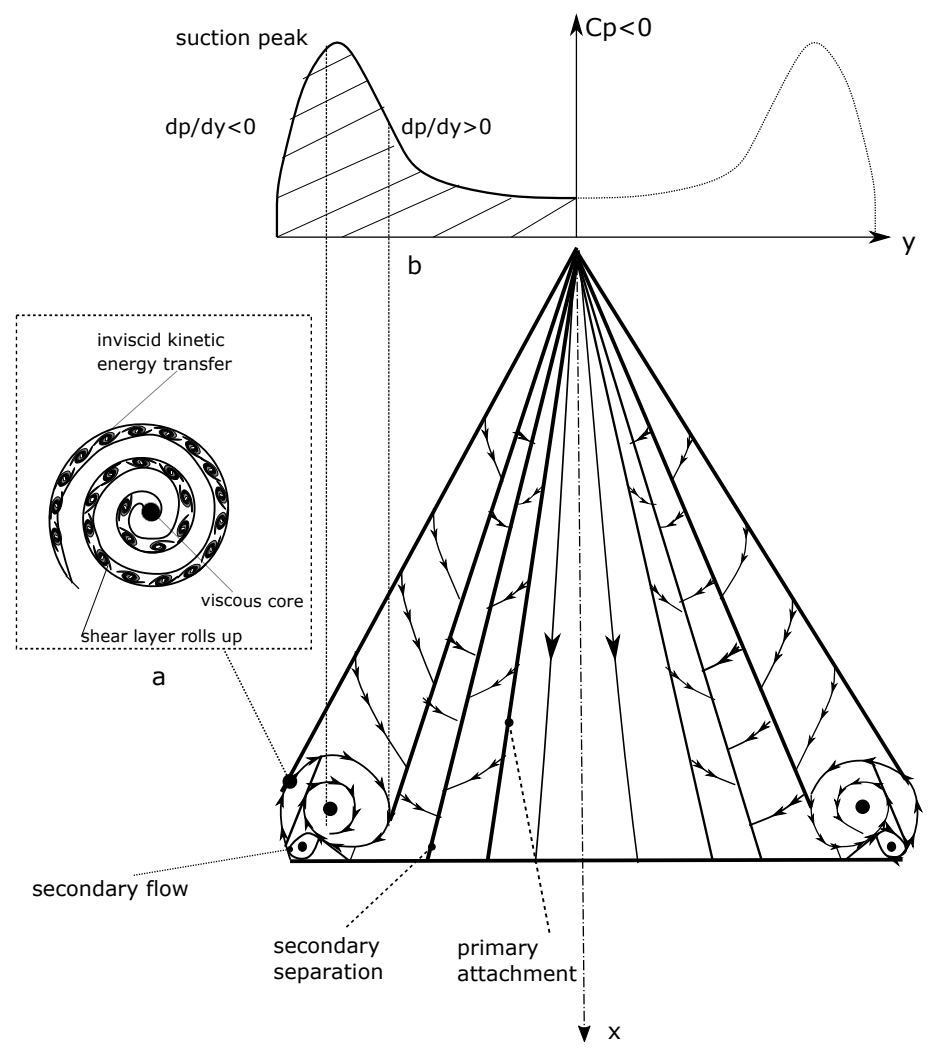

Figure 2. Streamline and flow topology over a DW: (a) details of the primary vortex; (b) windside pressure coefficient, $c_{p}$.

As shown in the figure, the rather high-speed flow induced by these vortices determines two large suction peaks on the wing leeside. Therefore, with the VL phenomenon, leading edge flow separation provides an additional $C_{L}$ contribution with respect to that predicted by the linear theory (Equation (1)) of Jones [27]. In particular, this extra contribution is referred to as the nonlinear increase of lift, due to its rapid increase with the AoA. This allows SA to approach runways with rather low landing speeds when flying at an AoA greater than about $5-10^{\circ}$ (depending on the leading edge radius) [27]. However, by further increasing the AoA, say up to about $30-40^{\circ}$ (depending on the wing $A R$ ), leading edge vortices can become unstable due to the adverse pressure gradient. This leads to the well-known vortex breakdown (or vortex burst) phenomenon that results in the loss of lift (i.e., wing stall) $[3,4,27]$. Breakdown has also characteristic frequencies that have been found to be related to dangerous wing or fin buffeting [22,24]. Therefore, numerical simulation of a complete SA configuration at the landing AoA provides a fingerprint of the aircraft regions potentially subjected to unsteadiness-induced effects.

Vortex-lift relies on a complex flowfield phenomenon. As shown in Figure 2, the flow topology features two coherent vortices anchored along the DW leading edge. The leading edge vortex creation is well documented in the literature $[6,21,23]$. At a high AoA, say about $\alpha=10^{\circ}$, the flow directed toward the wing leeside separates at the sharp leading edge (the lift is larger when the leading edge is sharper). As a result, two shear layers roll up and merge together by creating a local vorticity region (see Figure 2a) [22]. The vorticity induces the flow reattachment on the leeside of the wing and creates the primary vortex. Leading edge vortices exhibit an external inviscid rotational region and an internal viscous core; see Figure 2. The primary vortex is continually fed by the leading-edge-induced separation [21]. Looking at the primary attachment line shown in Figure 2 (i.e., the location 
of the primary flow reattachment), two different streamline patterns can be observed. Inboard of the attachment line, the flow is undisturbed and is directed toward the trailing edge. Outboard of the attachment line, flow is directed toward the leading edge. The primary vortex undergoes a secondary separation created by the boundary layer, wall roughness, and adverse pressure gradient. Eventually, the secondary flow separation is followed by a new reattachment forming a secondary vortex [27]. The strength of the secondary vortex is lower than the primary one, and it is counter-rotating with respect to the primary vortex.

The Polhamus theory models the VL contribution using a leading edge suction analogy [21]. According to this model, the total lift, $C_{L}$, is the result of the two contributions, namely $\left(C_{L}\right)_{p}$ and $\left(C_{L}\right)_{v}$, which are the potential and vortex-lift contributions, respectively.

$$
\left\{\begin{array}{l}
\left(C_{L}\right)_{p}=K_{p} \sin (\alpha) \cos ^{2}(\alpha) \\
\left(C_{L}\right)_{v}=K_{v} \sin ^{2}(\alpha) \cos (\alpha)
\end{array}\right.
$$

$K_{p}$ and $K_{v}$ are configuration-specific constants given by the vortex lattice solution and depend on the wing $A R$. Therefore,

$$
C_{L}=\left(C_{L}\right)_{p}+\left(C_{L}\right)_{v}=K_{p} \sin (\alpha) \cos ^{2}(\alpha)+K_{v} \sin ^{2}(\alpha) \cos (\alpha)
$$

Including the VL effects, the drag coefficient is:

$$
C_{D}=C_{L} \tan (\alpha)
$$

Thus, the drag polar reads:

$$
C_{D}=C_{D 0}+C_{L} \tan (\alpha)
$$

where $C_{D 0}$ is the zero-lift drag coefficient of the aircraft.

\subsection{Vortex Breakdown}

Delta-winged aircraft have a near-to-stall aerodynamic behaviour quite different if compared to more conventional low-swept configurations. Experimental observations evidenced two types of flow instabilities that affect the shear layer instability (KevinHelmholtz) and the helical mode instability [24]. When the AoA increases over a critical value (depending on the wing sweep angle), the shear layer instability destabilises the primary vortex. The sudden axial deceleration of the flow creates a stagnation point and, consequently, a region of reversed axial flow [28]. Shear stresses between the inner and outer flow layers of the primary vortex progressively reduce the angular rotation velocity of the core. Therefore, vorticity production is no longer sustained, and the vorticity axis re-orients from the axial to transverse direction, normal to the wing plane. The cross-sectional area of the leading edge vortex suddenly increases [6,29]. Flow starts to separate from the leeside and merges with other vortex structures by creating a multiscale vorticity field with a consequent disruption of the primary core. Experimental results evidenced that vortex breakdown arises in two different ways, namely bubble breakdown and spiral breakdown, depending on the wing $A R$. Bubble breakdown is characterized by a stagnation point on the vortex rotation axis, followed by fast fluid expansion and a recirculation bubble. The recirculation region creates a new vortex weaker than the preceding one. In the second case, spiral breakdown is caused by an abrupt deceleration of fluid flow and the formation of a stagnation point. Suddenly, near the stagnation region, the flow follows a spiral path. Generally, spiralling motion survives for two to three rounds; then, the flow evolves into a fully developed turbulence. 


\subsection{Aerodynamic Effect of Breakdown}

The effect of breakdown over the vortex-lift is not as evident until the secondary vortex undergoes separation. In this case, swirling flow no longer forms over the leading edge, and eventually, the total aerodynamic lift decreases [30]. In particular, one of the main issues of vortex breakdown is represented by vortex asymmetry. Any random disturbance originating over the leeside can be potentially a precursor of breakdown. The opposite rotation of the two vortices causes destructive interferences, with the consequent reduction of leeside depression. As a result, the fluid flow is freer to leave the wing body, thus causing the wing stall. This phenomenon also causes unstable roll moments for the aircraft.

\section{Aerodynamic Study of a Concorde-Like Aeroshape}

The present research work focuses on the aerodynamic appraisal of an SA carried out at very-low-speed conditions such as those expected at the landing phase. The aeroplane configuration under investigation is shown in Figure 3.
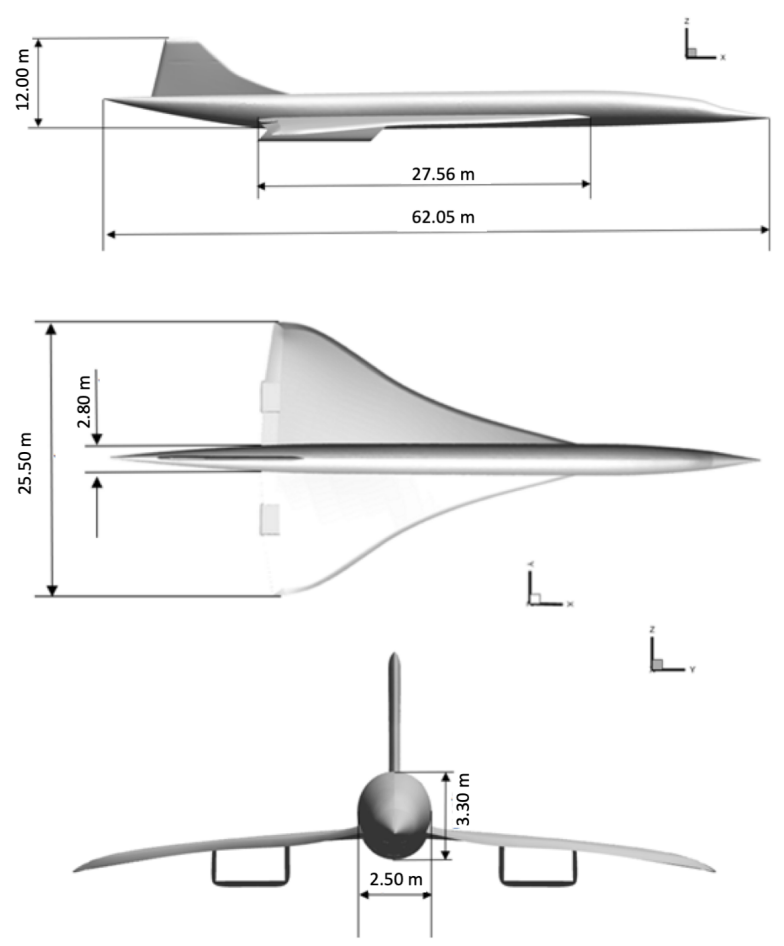

Figure 3. Aircraft configuration.

It features a Concorde-like aeroshape with an ogee double DW seamlessly integrated with a Sears-Haack body fuselage. A tailless delta configuration was assumed for similarity to previous design solutions, as used for the Concorde and the Tupolev Tu-144 aeroplanes.

Furthermore, sharp leading edges for the wing, tail, and fuselage to limit the wave drag penalty at supersonic speeds were also considered.

The aerodynamic performances were addressed at $M_{\infty}=0.24$, by means of thirteen steady-state, three-dimensional, incompressible, and fully turbulent Navier-Stokes (NS) flowfield simulations, according to the to the following conditions: $\alpha=0^{\circ}, 5^{\circ}, 10^{\circ}, 15^{\circ}, 20^{\circ}, 25^{\circ}$, $30^{\circ}, 35^{\circ}, 40^{\circ}, 45^{\circ}, 50^{\circ}, 55^{\circ}, 60^{\circ}$, at $\mathrm{z}=30 \mathrm{~m}, M_{\infty}=0.24, R e_{L_{r e f}}=1.6 \times 10^{8}, P_{\infty}=100,965.4 \mathrm{~Pa}$, $\rho_{\infty}=1.221 \mathrm{~kg} / \mathrm{m}^{3}, T_{\infty}=287.95 \mathrm{~K}$.

\subsection{Computational Domain and Grids}

Flowfield simulations were carried out on unstructured hybrid meshes having hexagonal cells in the flowfield domain and prisms in the boundary layer, as shown in Figure 4. 


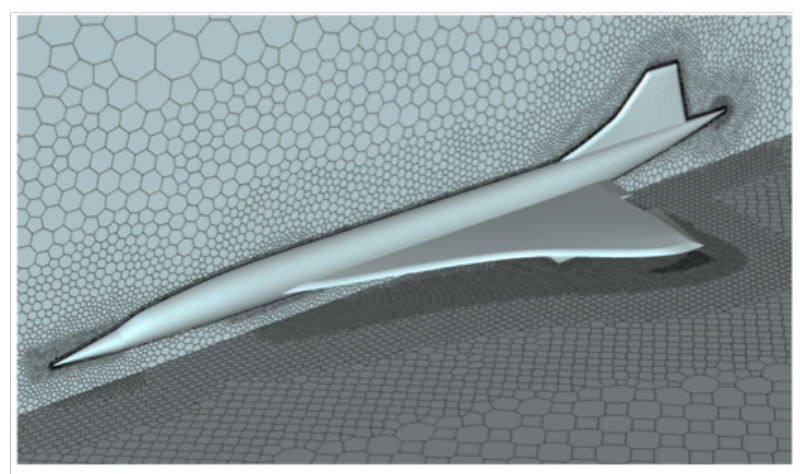

a

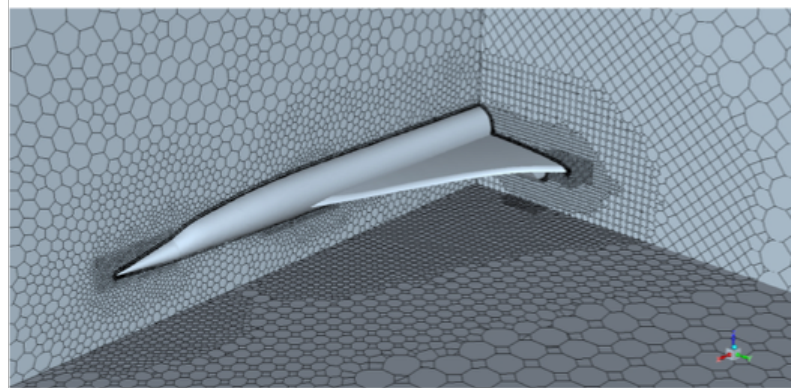

b
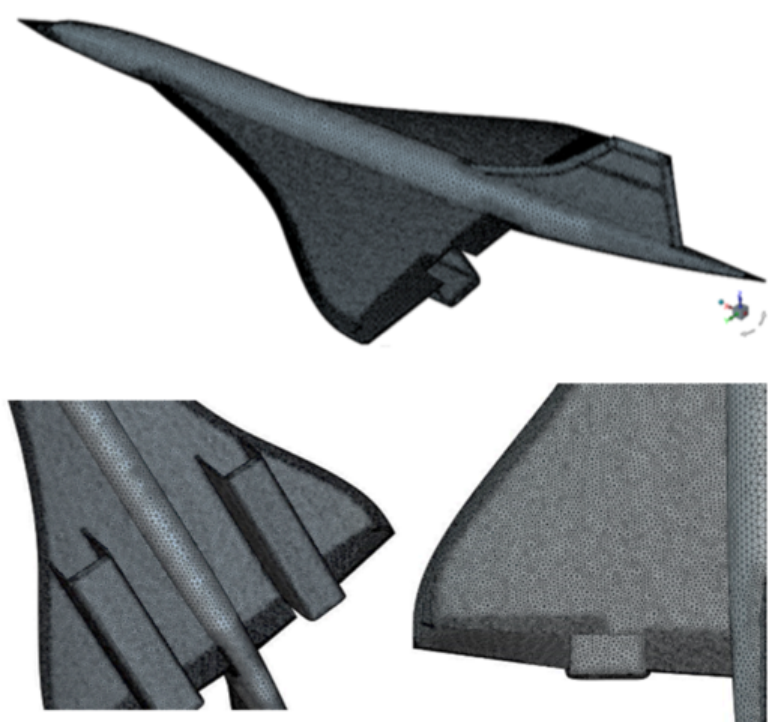

C

Figure 4. (a) Volume polyhedral mesh; (b) detail of mesh refinement; (c) surface mesh.

A body of influence surrounding the vehicle for mesh refinement, especially around the leading edge, was considered (see Figure $4 a, b$ ). The surface grid is provided in Figure 4c, with the details of the triangular mesh.

The half-body grid consisted of about $4 \times 10^{6}$ cells, according to a grid independence study performed on three subsequent levels of mesh refinement.

Finally, in order to accurately describe high gradients of the flow properties within the boundary layer, the grid featured a minimum wall spacing equal to $10^{-6} \mathrm{~m}$ to allow for $y^{+}=O(1)$ and enough points to describe the viscous sublayer. 


\subsection{CFD Modelling and Results}

Steady-state RANS simulations were performed adopting the pressure-based solver, available in ANSYS-FLUENT. The perfect gas model was used for air, with specific heat at constant pressure equal to $c p=1006 \mathrm{~J} / \mathrm{kgK}$ and viscosity provided by the Sutherland law. Air thermal conductivity was assumed constant, $k=0.0242 \mathrm{~W} / \mathrm{mK}$.

Finally, RANS closure was performed using the shear-stress transport (SST) $k$ - $\omega$ model. As far as wall boundary conditions are concerned, the pressure farfield and pressure outlet conditions were used at the domain inlet and outlet, respectively. The adiabatic wall boundary condition was applied to the aircraft aeroshape.

Convective fluxes were discretized adopting second-order Roe flux difference splitting (FDS), while diffusive fluxes were discretized considering a cell-centred scheme. The solution steering (SS) algorithm in FLUENT determined the Courant number (CN) during the simulations. In order to ensure a steady-state-converged solution, SS automatically changes some solver parameters and progressively increases the CN. In particular, SS allows the solver to not exceed the assigned maximum CN (usually 200 for subsonic flow) and to use a $\mathrm{CN}$ less than the initial value if the solution diverges.

The aircraft aerodynamics, addressed for a clean configuration and longitudinal flight conditions only, is summarized by means of the pressure distributions, flowfield visualisations, and behaviour of the aerodynamic coefficients in the pre-stall and poststall conditions.

The aerodynamic coefficients (i.e., $C_{L}, C_{D}$, and $C_{M}$ ) read:

$$
\begin{gathered}
C_{i}=\frac{F_{i}}{q_{\infty} S_{r e f}} \quad i=L, D \\
C_{M}=\frac{M}{q_{\infty} S_{r e f} l_{r e f}}
\end{gathered}
$$

where the reference surface, $S_{r e f}=332.60 \mathrm{~m}^{2}$, and length, $l_{r e f}=27.66 \mathrm{~m}$, are the wing planform area and the wing mean aerodynamic chord (MAC), respectively, while $q_{\infty}$ is the dynamic pressure.

According to the ISO 1151 standard, force coefficients (i.e., $C_{D}$ and $C_{L}$ ) are expressed with respect to the wind reference frame $\left(X_{W}, Y_{W}, Z_{W}\right)$, while the pitching moment coefficient, $C_{M}$, refers to the body reference frame $\left(X_{B}, Y_{B}, Z_{B}\right)$; see Figure 5 . The pole for moment reduction was assumed at both the aircraft nose and at several percentages of the MAC length.

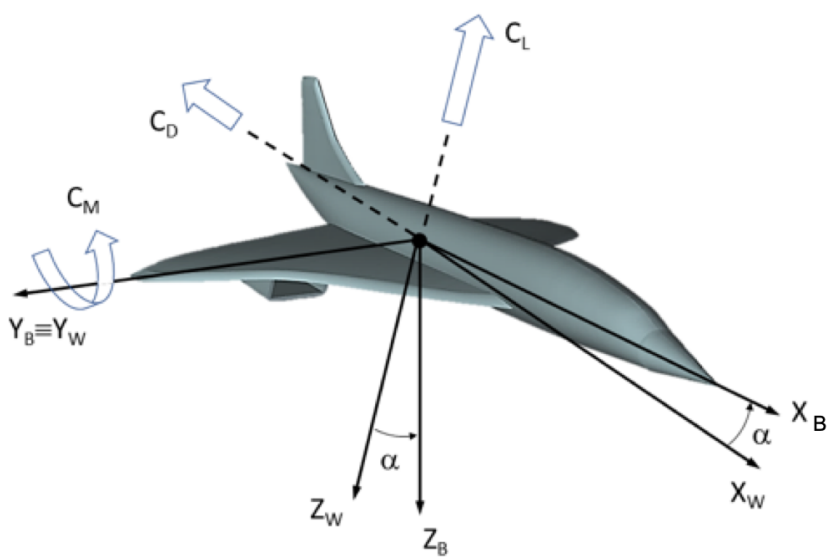

Figure 5. Body $\left(X_{B}, Y_{B}, Z_{B}\right)$ and wind $\left(X_{W}, Y_{W}, Z_{W}\right)$ reference frames.

The contours of the pressure distributions that take place over the aircraft leeside at $\alpha=0^{\circ}, 10^{\circ}, 20^{\circ}, 30^{\circ}$ are shown in Figure $6 \mathrm{a}-\mathrm{d}$. 


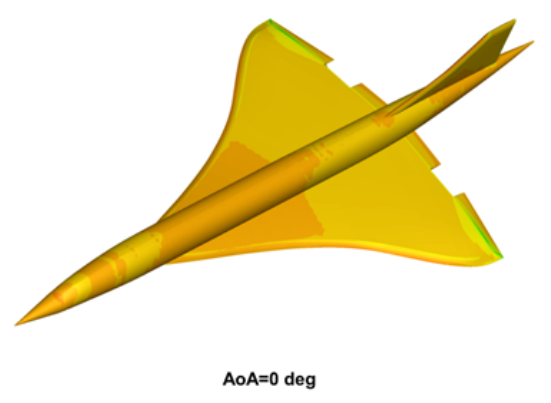

a

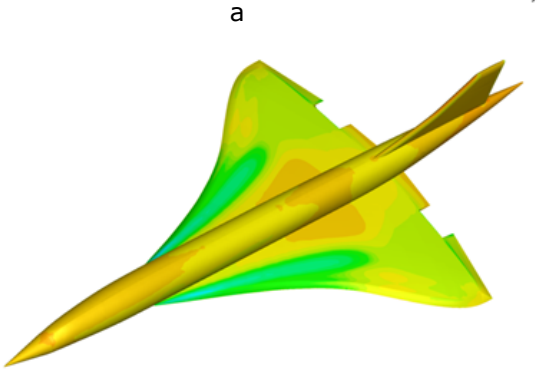

$A \circ A=20$ deg

C

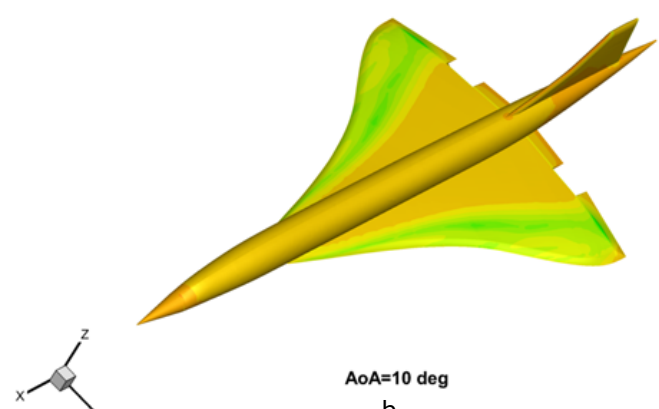

b

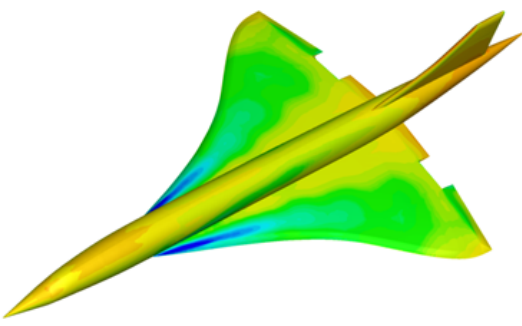

$A \circ A=30$ deg

d

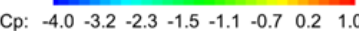

Figure 6. Pressure distribution on the aircraft leeside at different $\mathrm{AoAs}(\mathbf{a}) \mathrm{AoA}=0^{\circ}$; (b) $\mathrm{AoA}=10^{\circ}$; (c) $\mathrm{AoA}=20^{\circ} ;(\mathrm{d}) \mathrm{AoA}=30^{\circ}$.

These contours highlight that for all the AoAs, except $\alpha=0^{\circ}$, airflow at the leading edge separates and curls close to the wing tips. According to Figure 2, the effect of the vortices' development is the low-pressure zones at the wing leeside; see Figure $6 \mathrm{~b}-\mathrm{d}$.

The presence of flow vortical structures at the wing leeside can be further appreciated by looking at Figure $7 \mathrm{a}-\mathrm{d}$, where the mean vorticity distributions in different wing crosssections and for $\alpha=10^{\circ}, 20^{\circ}, 30^{\circ}$, and $40^{\circ}$ are shown.

As one can see, increasing the AoA (see Figure $7 \mathrm{~b}$ ), the primary vortex is continually fed by the vorticity originating on the wing leading edge.

Then, flow vorticity is immediately conveyed downstream by the chordwise flow. Kinetic energy, momentum, and mass are exchanged between the vortices (primary and secondary) and are transported downstream.

In particular, a dual-vortex structure is clearly observed at $\alpha=10^{\circ}, \alpha=20^{\circ}$, and $\alpha=30^{\circ}$, which regroups the primary and the secondary core [6,23], while at $\alpha=40^{\circ}$, the picture changes, thus highlighting a gentle post-stall aerodynamic condition. Therefore, the trends of the lift, drag, and pitching moment coefficients versus AoA are expected to change passing from $\alpha=30^{\circ}$ to $\alpha=40^{\circ}$, as will be discussed later.

Further, at $\alpha=20^{\circ}$, shear layer instabilities overcome the stabilizing effect due to the downward transport of the vorticity, and breakdown starts. At $\alpha>20^{\circ}$, the vorticity rapidly diffuses in the cross-sectional plane of the wing, as shown in Figure $7 \mathrm{~d}$.

The inboard vortex represents the primary flow as it appears by looking at the stronger suction peaks shown in Figures $8-10$ for $\alpha=10^{\circ}, 20^{\circ}$, and $30^{\circ}$, respectively.

In these figures, vorticity contours evaluated at three different aircraft cross-sections, namely $x=-25 \mathrm{~m}, x=-35 \mathrm{~m}$, and $x=-45 \mathrm{~m}$, are associated with the corresponding pressure coefficient variations in order to appreciate the vortex strength and relative flow suction that determine the VL phenomenon. 

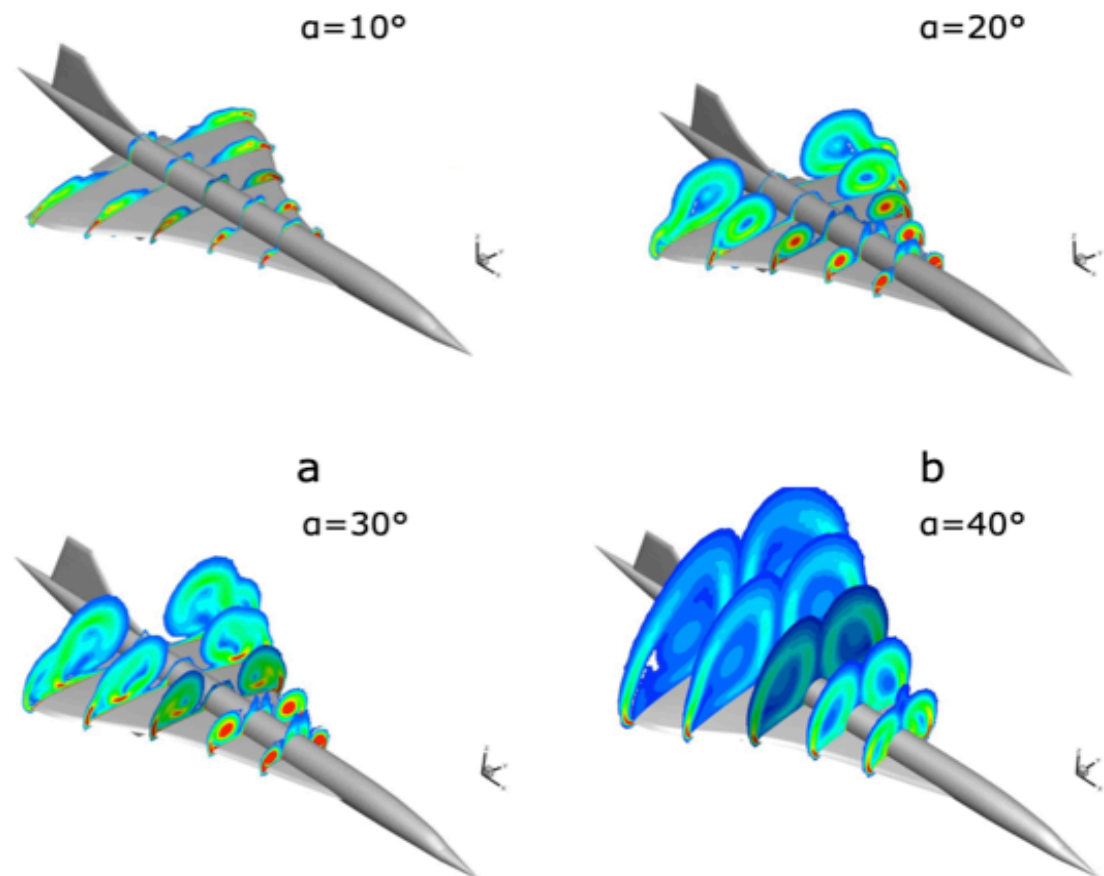

C

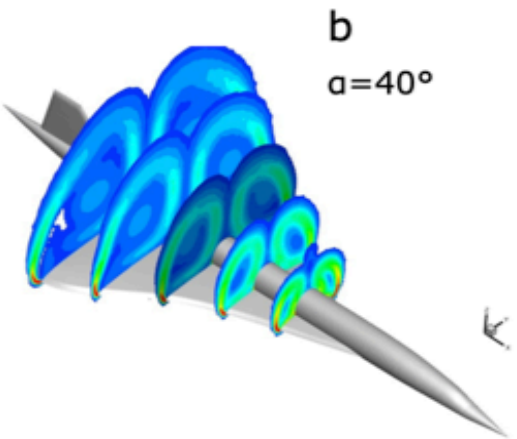

d

Vorticity Magnitude (1/s): $0 \quad 21.052642 .105363 .157984 .2105105 .263126 .316147 .368188 .421189 .474$

Figure 7. Vorticity field on different aircraft cross-sections $(-45,-25) \mathrm{m}$ and at different AoAs. (a) $\mathrm{AoA}=10^{\circ} ;(\mathbf{b}) \mathrm{AoA}=20^{\circ}$; (c) $\mathrm{AoA}=30^{\circ}$; (d) $\mathrm{AoA}=40^{\circ}$.

As expected, the higher the AoA, the larger the flow suction and the vorticity at the wing leeside are.

Moreover, vortex strength and flow suction decrease as the airstream proceeds towards the wing's trailing edge (i.e., the suction force is the strongest near the wing apex).

Figures 9 and 10 show that breakdown is characterised by pressure oscillations of the mean field. Specifically, as far as the AoA increases, the primary vortex progressively merges with the secondary one, and the vortex axis moves inboard toward the fuselage.

The increase in vortex strength influences the aerodynamic performance (i.e., forces and moments) as far as the AoA changes between $\alpha=10^{\circ}$ and $\alpha=30^{\circ}$.

This leads to an aerodynamic behaviour for the aircraft significantly different from the classical aerodynamics of high-AR wing aeroplanes at the same low-speed flow. For instance, the $C_{L}$ versus $\alpha$ characteristic is not linear and features rather high values and a gentle stall condition at a very high AoA.

The CFD results confirmed that the aircraft's low-speed aerodynamics is strongly influenced by the DW. Through the VL phenomenon, this allows low-speed landings without the support of high-lift devices, as needed in the case of conventional high-AR wing aeroplanes.

Moreover, the low AR of the DW represents a figure of merit at high speeds as well, since it allows limiting the unavoidable increase in supersonic drag. Therefore, the DW design solution reveals the right compromise between the low-speed and high-speed performance of SA.

For a better understanding of the VL phenomenon, a detailed description of the flow vortices that develop over the wing leeside at $\alpha=20^{\circ}$ is provided in Figure 11. Here, surface streamlines are superimposed on pressure isosurfaces, thus highlighting the flow attachment and separation zones of both the primary and secondary vortices. 

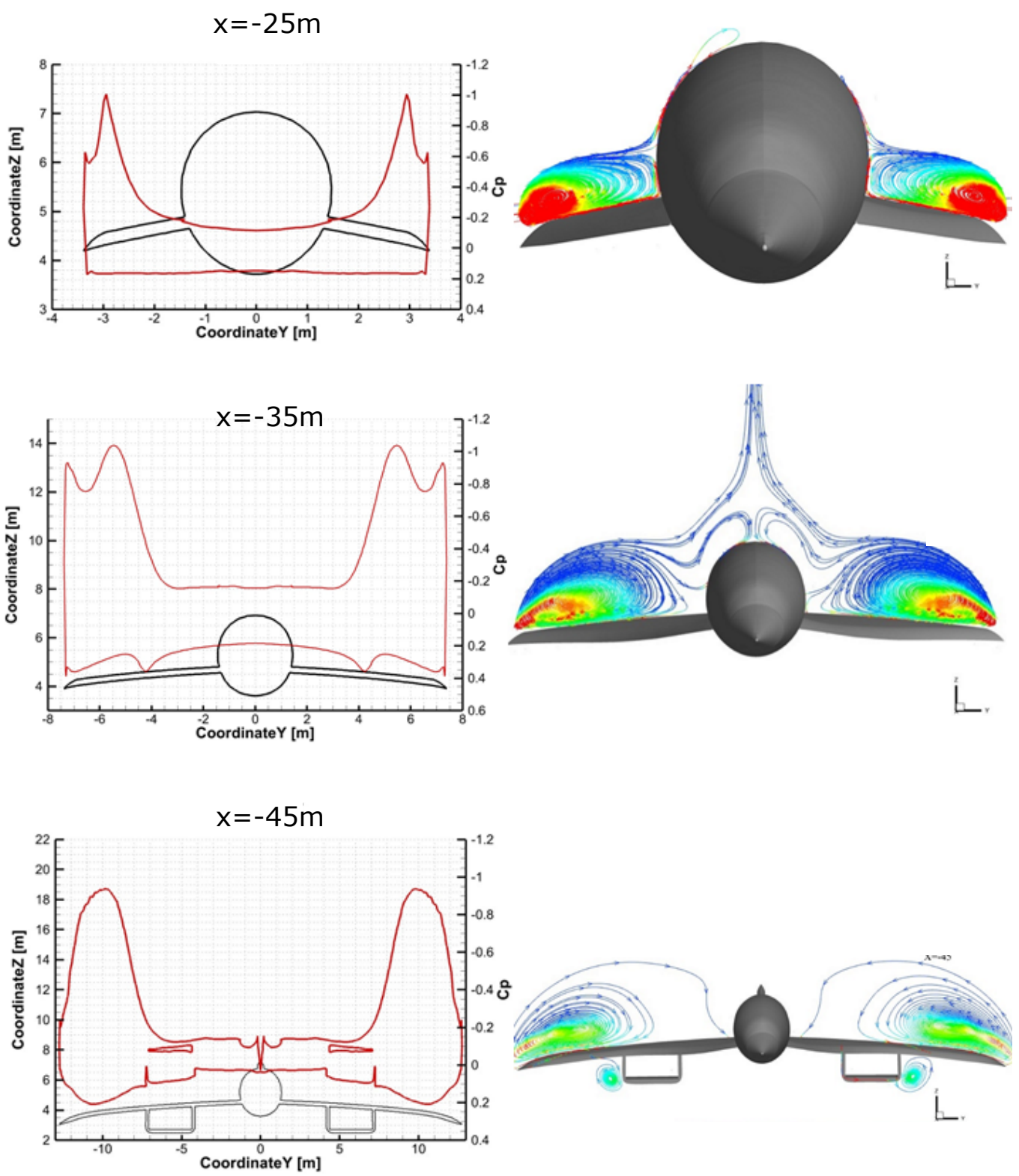

Vorticity Magnitude (1/s)

$0 \quad 21.052642 .105363 .157984 .2105105 .263126 .316147 .368168 .421189 .474$

Figure 8. Flowfield results at $\alpha=10^{\circ}$. Pressure distribution (left) and vorticity magnitude (right).

The streamlines representing the attachment regions divide the undisturbed flow, directed toward the trailing edge, from the primary flow headed toward the wing tips. However, the primary flow is affected by the adverse pressure gradient and the skin-friction (see Figure 11).

Finally, also the primary flow separates from the wing and reattaches, creating a weaker (secondary) vortex.

The aerodynamic coefficients in the body and wind reference frames are summarized in Table 2, while the curves of $C_{L}$ and $C_{D}$ versus $\alpha$ are also provided in Figure 12. Here, a focus on the lift and drag coefficients up to $\alpha=30^{\circ}$ is also reported and compared with Polhamus' force coefficients; see Equations (3) and (4), respectively. 

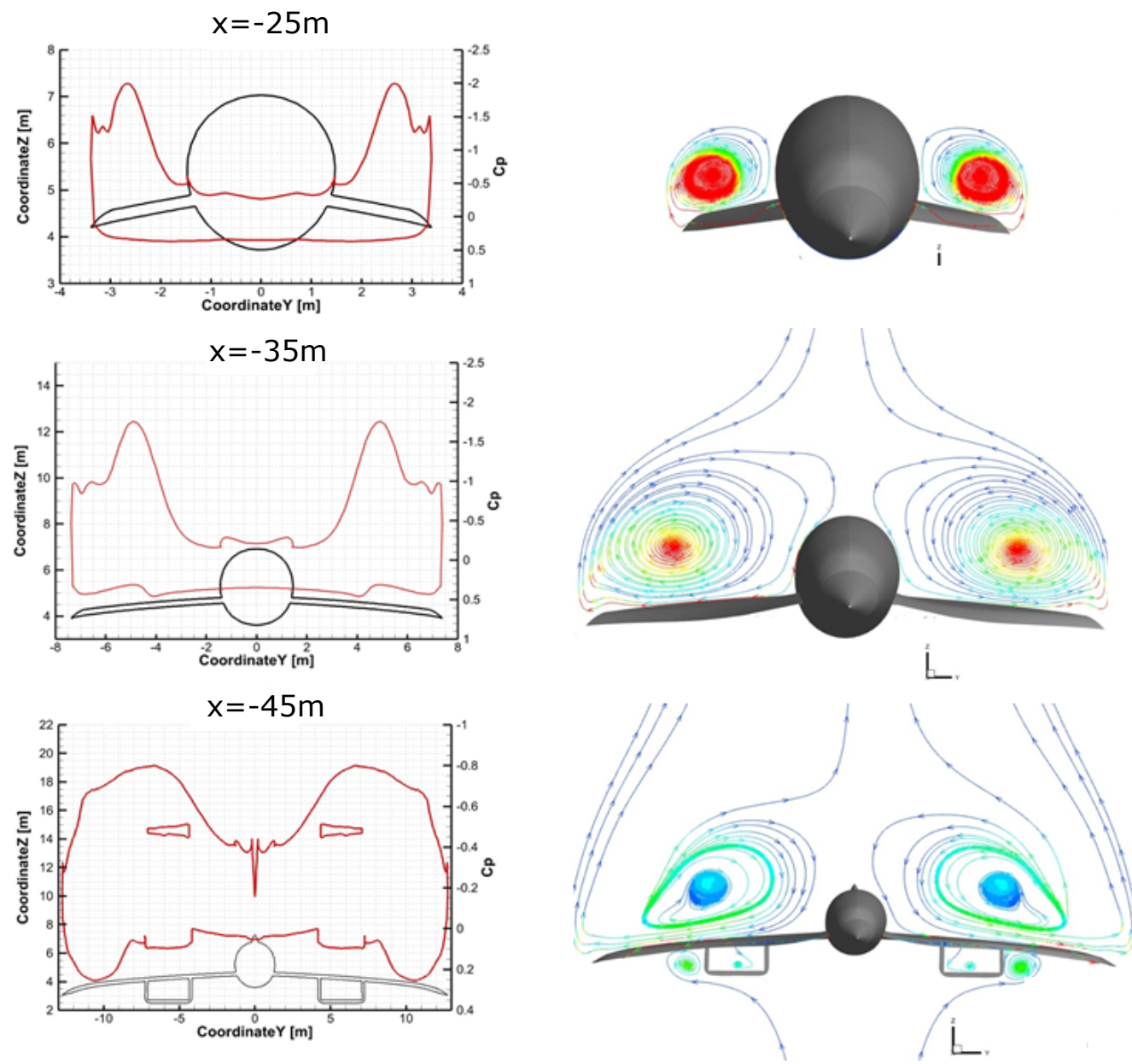

Vorticity Magnitude (1/s): $0 \quad 21.052642 .105363 .157984 .2105105 .263126 .316147 .368168 .421189 .474$

Figure 9. Flowfield results at $\alpha=20^{\circ}$. Pressure distribution (left) and vorticity magnitude (right).

Table 2. Aircraft aerodynamics.

\begin{tabular}{cccccccc}
\hline $\begin{array}{c}\alpha \\
(\mathrm{deg})\end{array}$ & $\begin{array}{c}C_{N} \\
(-)\end{array}$ & $\begin{array}{c}C_{A} \\
(-)\end{array}$ & $\begin{array}{c}C_{M N O S E} \\
(-)\end{array}$ & $\begin{array}{c}C_{L} \\
(-)\end{array}$ & $\begin{array}{c}C_{D} \\
(-)\end{array}$ & $\begin{array}{c}C_{M 0.52 c} \\
(-)\end{array}$ & $\begin{array}{c}L / D \\
(-)\end{array}$ \\
\hline 0 & 0.1251 & 0.02278 & -0.1896 & 0.1251 & 0.0228 & -0.0479 & 5.4868 \\
5 & 0.3505 & 0.01042 & -0.4773 & 0.3473 & 0.0408 & -0.0859 & 8.5123 \\
10 & 0.6571 & 0.00438 & -0.8762 & 0.6464 & 0.1184 & -0.1359 & 5.4595 \\
15 & 0.9710 & -0.00143 & -1.3271 & 0.9382 & 0.2499 & -0.1733 & 3.7543 \\
20 & 1.2401 & 0.00453 & -1.5428 & 1.1637 & 0.4284 & -0.1778 & 2.7166 \\
25 & 1.4937 & -0.00508 & -1.8796 & 1.3559 & 0.6267 & -0.2188 & 2.1636 \\
30 & 1.7743 & -0.01085 & -2.2389 & 1.5420 & 0.8778 & -0.2667 & 1.7565 \\
35 & 1.6850 & -0.00603 & -2.0999 & 1.3837 & 0.9615 & -0.2265 & 1.4391 \\
40 & 1.5515 & 0.00373 & -1.9439 & 1.1861 & 1.0001 & -0.2179 & 1.1860 \\
45 & 1.5089 & 0.00447 & -1.8832 & 1.0574 & 1.0701 & -0.2045 & 0.9881 \\
50 & 1.4049 & 0.00478 & -1.7543 & 0.8971 & 1.0762 & -0.1912 & 0.8336 \\
55 & 1.4448 & 0.00654 & -1.8189 & 0.8223 & 1.1873 & -0.2119 & 0.6926 \\
60 & 1.4928 & 0.00146 & -1.8780 & 0.7451 & 1.2935 & -0.2175 & 0.5760 \\
\hline
\end{tabular}



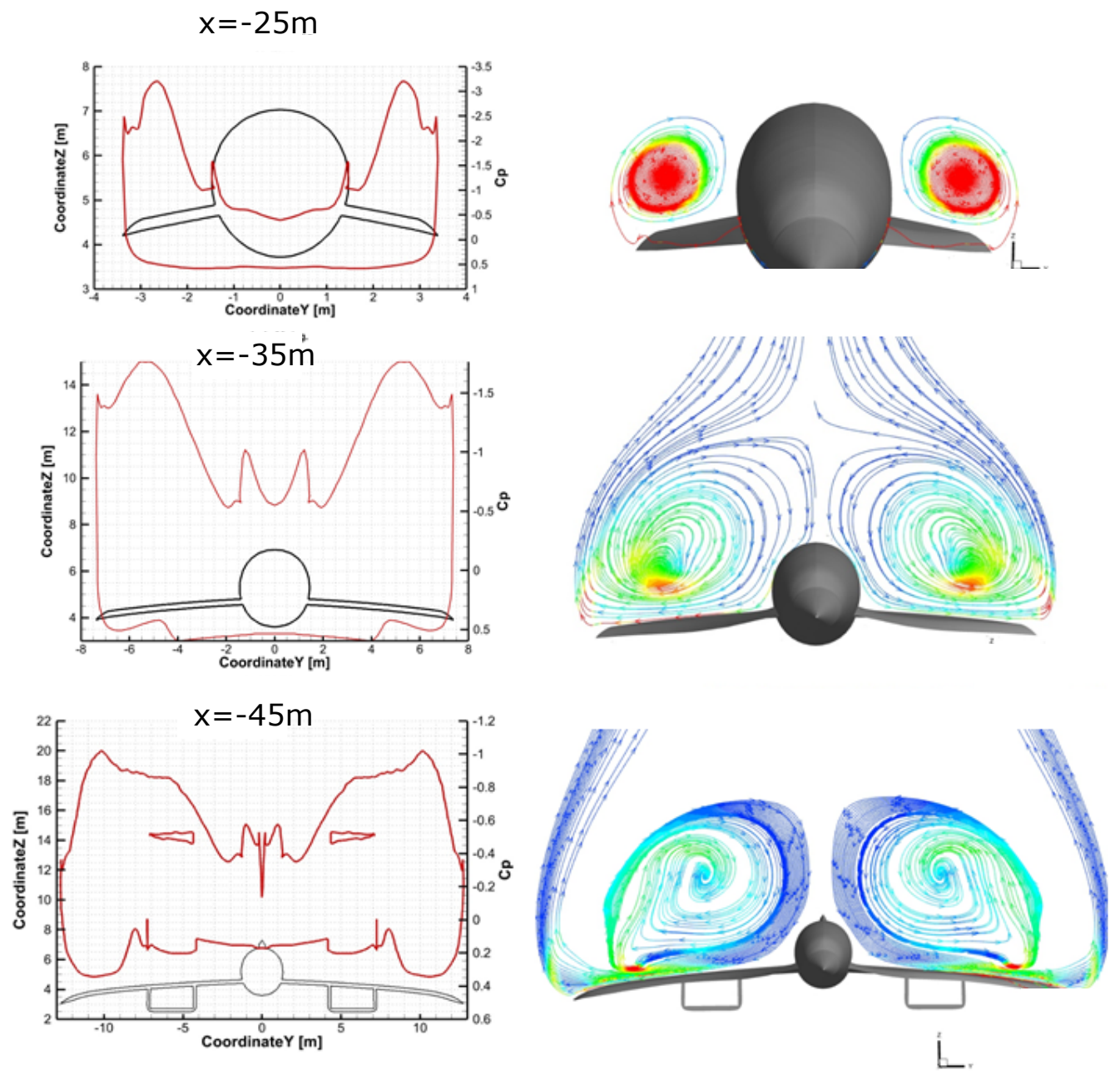

Vorticity Magnitude (1/s): $\quad 0 \quad 21.052642 .105363 .157984 .2105105 .263126 .316147 .368168 .421189 .474$

Figure 10. Flowfield results at $\alpha=30^{\circ}$. Pressure distribution (left) and vorticity magnitude (right).

The VL effect reflects over the aerodynamic performance at about $\alpha=10^{\circ}$, where the lift coefficient departs from the classical (low-speed) linear trend. Due to VL, $C_{L}$ increases up to $\alpha=30^{\circ}$, where it takes on its maximum value. Therefore, at a higher AoA, the lift begins to lower, thus highlighting a gentle post-stall condition, as expected. Similarly, the aircraft drag increases according to a quadratic trend until $\alpha=30^{\circ}$, where there is a change in the slope of the curve due to the VB phenomenon, as expected. Further, CFD and Polhamus' force coefficients provided in Figure 12c, d are in agreement with each other ( $C_{L}$ and $C_{D}$ at $\alpha=0^{\circ}$ are added to the Polhamus coefficients).

Aircraft drag polar is reported in Figure 13, where the CFD results are compared with the results provided by Equation (5). As one can see, the numerical and analytical results compare quite well. 

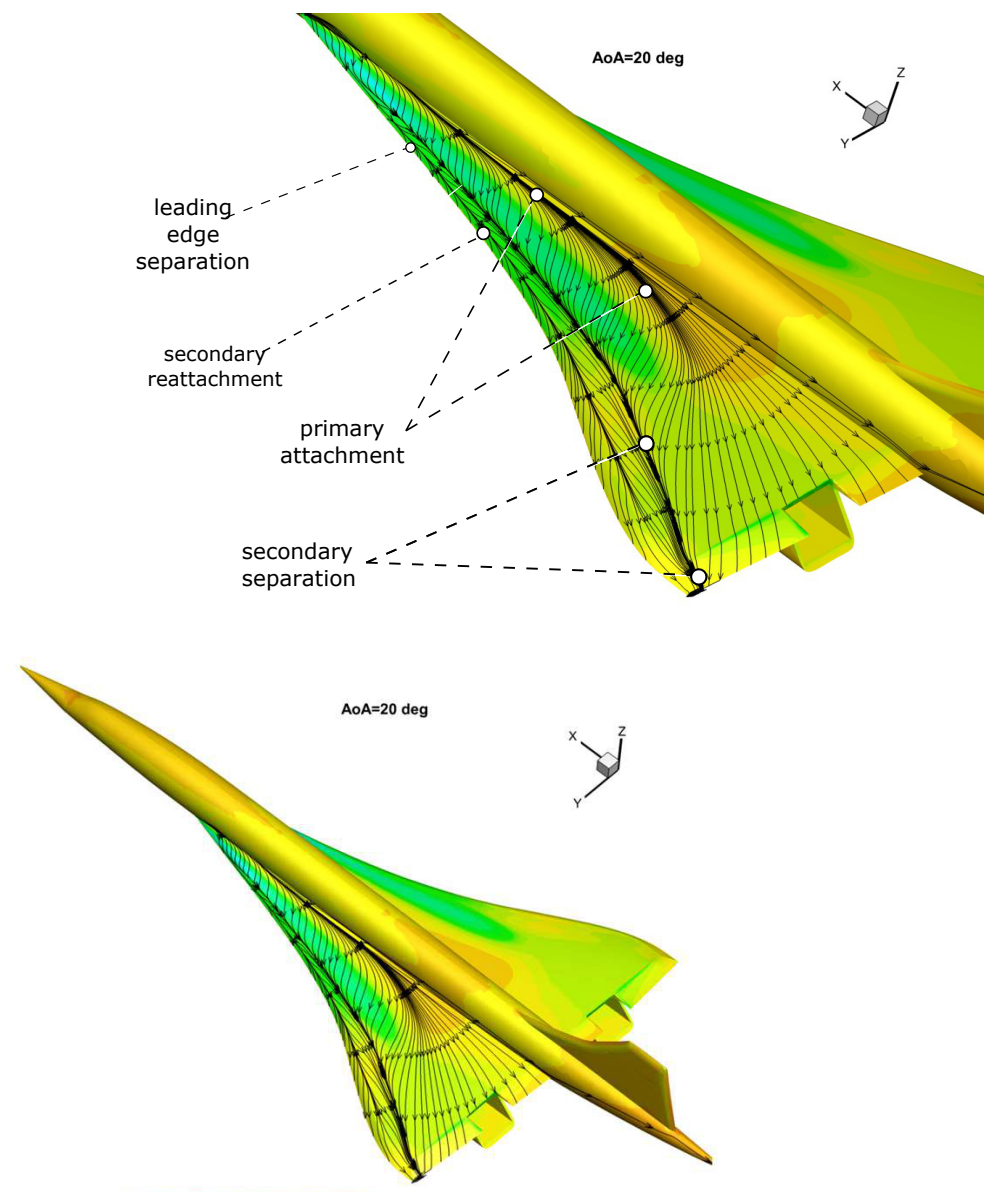

Cp: $-4.0-3.2-2.3-1.5-1.1-0.7 \quad 0.2 \quad 1.0$

Figure 11. Pressure distribution on the aircraft leeside at $\alpha=20^{\circ}$ with surface streamlines.
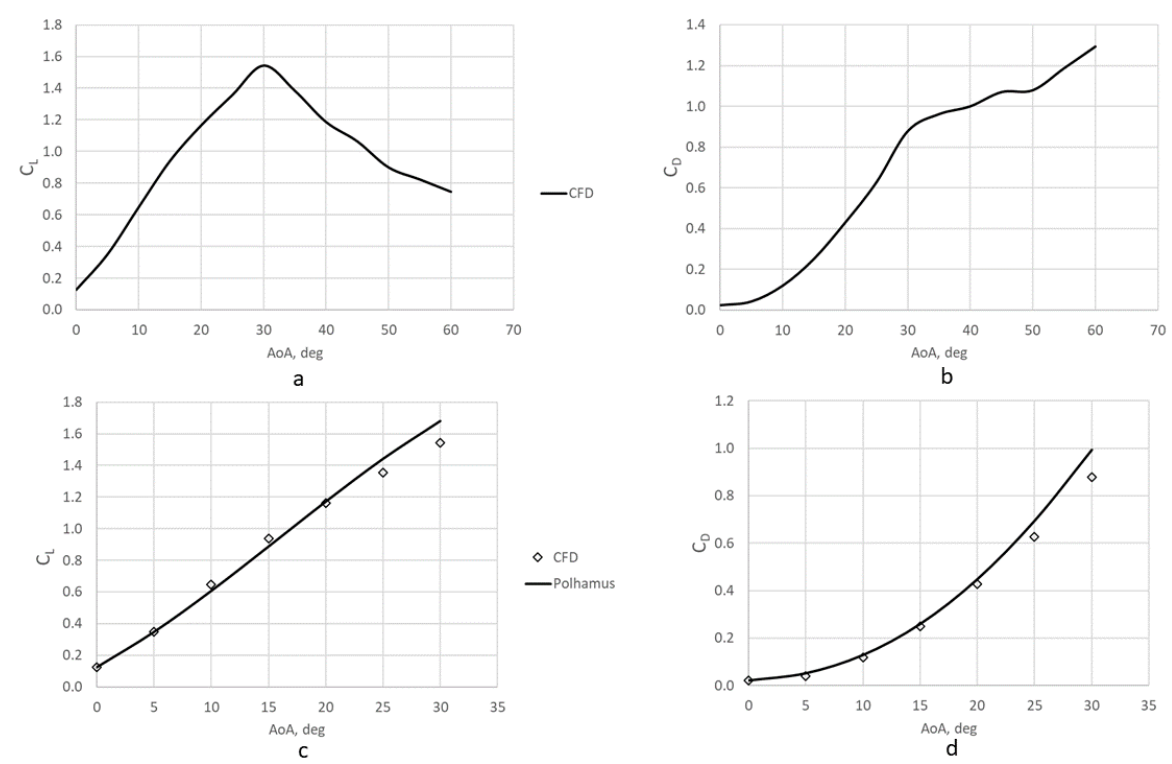

Figure 12. (a,b) Lift and drag coefficients; (c,d) comparisons between CFD and Polhamus' force coefficients. 


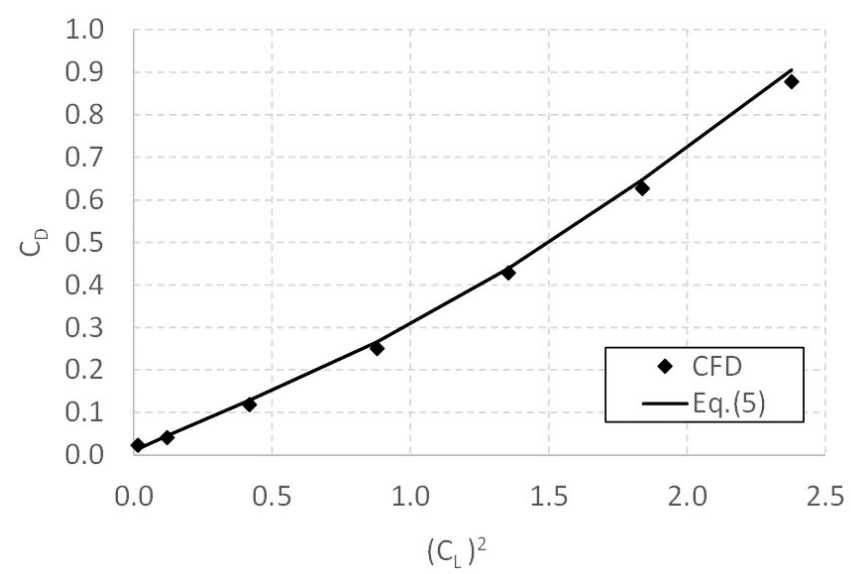

Figure 13. Aircraft's drag polar up to $\alpha=30^{\circ}$.

Finally, the curves of the aircraft pitching moment versus $\alpha$ and for different pole positions, namely $50 \%, 55 \%$, and $60 \%$ of MAC, are reported in Figure 14 .

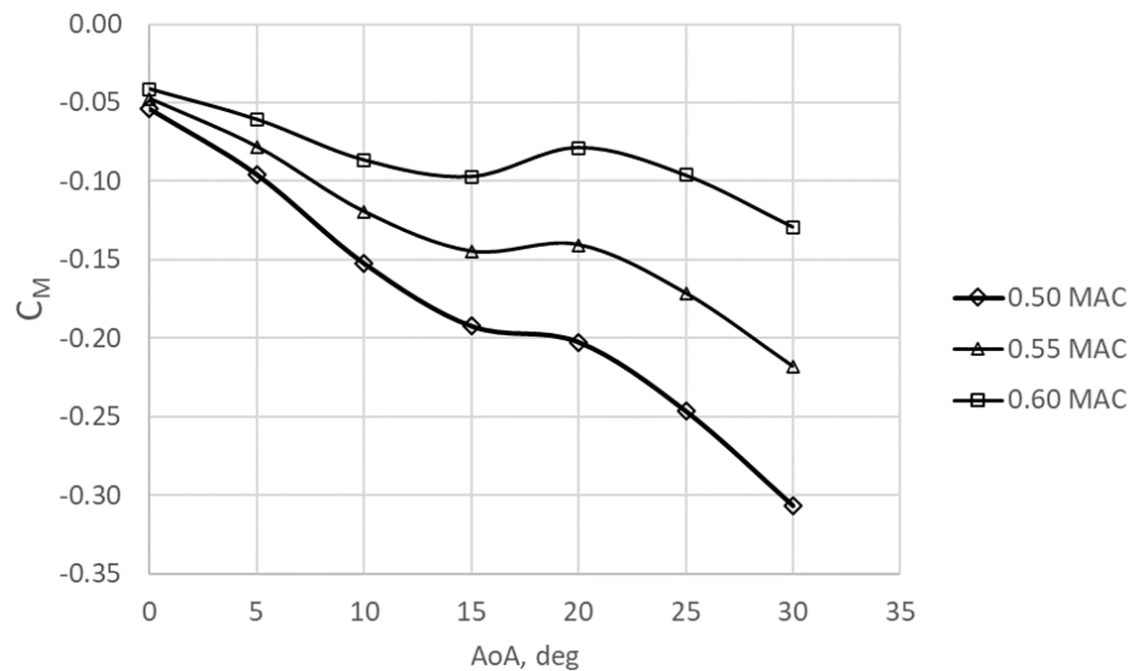

Figure 14. Aircraft's pitching moment up to $\alpha=30^{\circ}$. Pole position at $50 \%, 55 \%$, and $60 \%$ of MAC.

These curves refer to the SA in the clean configuration. As shown, the aircraft is statically stable (i.e., $C_{M_{\alpha}}<0$ ) in longitudinal flight conditions in two ranges of the AoA, namely $0^{\circ} \leq \alpha \leq 15^{\circ}$ and $20^{\circ} \leq \alpha \leq 30^{\circ}$.

\subsection{Flowfield at Breakdown}

The complex flowfield evolution induced by the DW aeroshape is shown in Figure 15, where a detailed three-dimensional visualisation of flow streamlines at $\alpha=10^{\circ}, 20^{\circ}$, and $30^{\circ}$ is provided. 

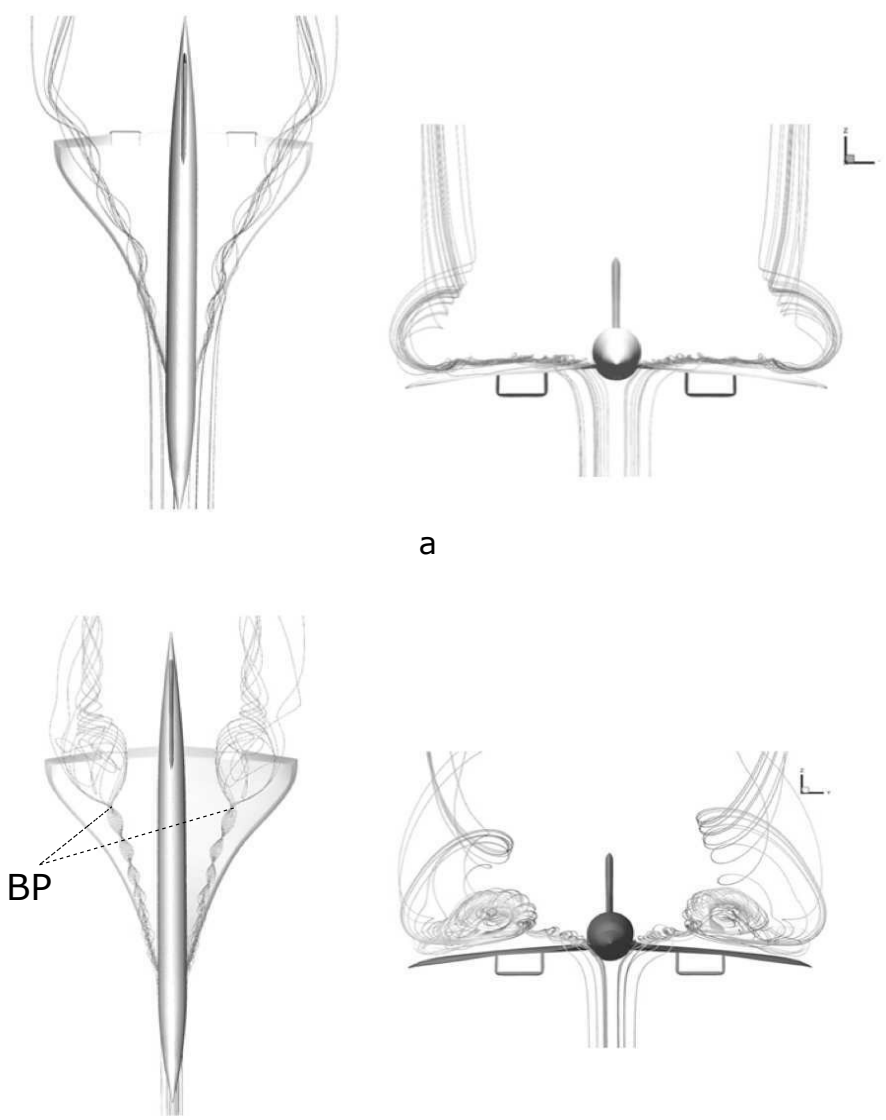

b
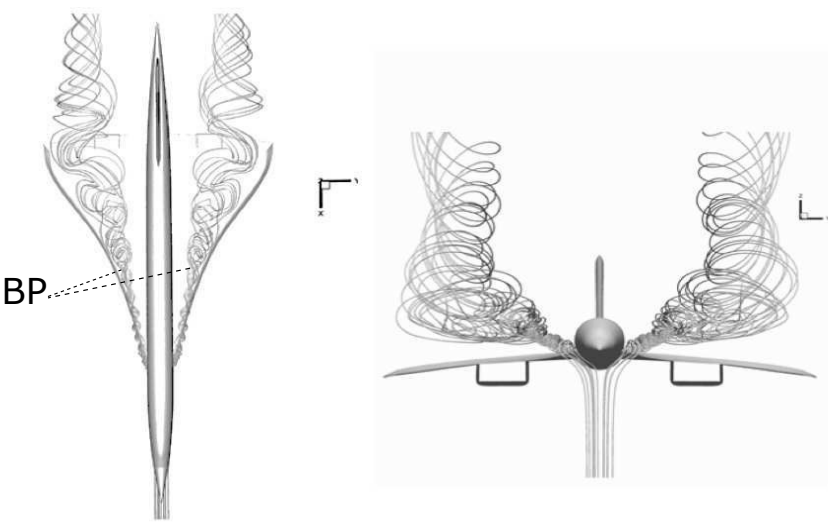

c

Figure 15. Flowfield streamlines at (a) $\alpha=10^{\circ}$, (b) $20^{\circ}$, and (c) $30^{\circ}$.

As shown, the flowfield over the wing assumes a complex topology as soon as the AoA increases.

At $\alpha=10^{\circ}$, in fact, the flow is attached with no VB; see Figure 15a. Here, the primary vortex appears stable and is convected downward. At $\alpha=20^{\circ}$, however, the VB phenomenon occurs near the trailing edge, as highlighted by the burst point (BP) location; see Figure $15 \mathrm{~b}$. For $15^{\circ} \leq \alpha \leq 20^{\circ}$ (see Figure 14), the aircraft is statically unstable. As mentioned, the onset of breakdown is at about $\alpha=15^{\circ}$ and causes a rapid deceleration of the vortex core. 
However, $\alpha=20^{\circ}$ flow reorganises, and the velocity fluctuations affects only the downstream region of the burst point (bubble-like separation). Therefore, the aircraft static stability is preserved up to $30^{\circ}$, where as shown in Figure $15 \mathrm{c}$, the BP moves closer to the wing's leading edge. At this point, the primary and secondary vortices merge, the velocity fluctuations encloses also the upward BP flow region, and a diffuse region of vorticity in the transverse direction in Figure 15c is observed. Therefore, wing stall is expected, as confirmed by the lift coefficient characteristics shown in Figure 12.

As a consequence, the CFD results confirmed that the gradual increase of the AoA causes the vortex $\mathrm{BP}$, which is far behind the trailing edge at the beginning, to move gradually upstream. In particular, the BP takes place because, at a certain point along with the chordwise flow, the axial velocity in the vortex core is reduced and the vortex becomes unstable. The vortex core bursts, and the induced flow suction on the wing disappears, i.e., a condition similar to wing stall is observed.

Finally, flow visualization shows the vortex bursting as a sudden bubble growth of the vortex core, called bubble breakdown.

\section{Conclusions}

The aerodynamics of a supersonic aircraft at low-speed conditions, expected during the approach phase, was investigated. The aircraft configuration featured a Concorde-like aeroshape with a sharp leading edge delta-ogee wing, seamlessly integrated on a SearsHaack body fuselage. This analysis was motivated by the renewed interest of the world market in civilian supersonic transportation and the need to assess the aircraft aerodynamic performance of a low-aspect-ratio wing under very-low-speed conditions.

The drag polar at $M_{\infty}=0.24$ and in longitudinal flight and motor-off conditions were evaluated with steady, three-dimensional, and fully turbulent computational fluid dynamics simulations. The Polhamus suction theory was also considered in the evaluations for comparison purposes.

Flowfield computations confirmed the classical low-speed behaviour expected for delta wings as, for instance, the well-known vortex-lift phenomenon. Several flowfield features past the aircraft were addressed at several angles of attack and on different aeroplane cross-sections. The vorticity and pressure distributions on the wing leeside demonstrated the flow sensitivity to external perturbations, which can drive to vortex breakdown and, therefore, wing stall. The vortex bursting point was found to be influenced by the angle of attack, as expected. Specifically, the onset of the complex and multiscale regions of vorticity was related to specified values of the angle of attack.

In particular, the numerical results highlighted that the vortex-lift effect reflected over the aircraft aerodynamic performance at about $\alpha=10^{\circ}$, where the lift coefficient departed from the classical low-speed linear trend. Due to vortex-lift, the lift force increased until $\alpha=30^{\circ}$, where it took on its maximum value equal to about 1.6. Therefore, at a higher AoA, the lift began to lower, thus highlighting a gentle post-stall condition. Similarly, the aircraft drag increased according to a quadratic trend until $\alpha=30^{\circ}$, where there was a change in the slope of the curve due to the vortex-lift phenomenon. A preliminary study of longitudinal stability showed that statically stable landing flight attitudes for the aircraft in the clean configuration were found in the ranges of the angle of attack of $0^{\circ} \leq \alpha \leq 15^{\circ}$ and $20^{\circ} \leq \alpha \leq 30^{\circ}$.

Finally, comparisons of the numerical and Polhamus' force coefficients pointed out the good agreement between the flowfield investigations and the analytical approach.

Author Contributions: Conceptualization, G.P.; methodology and software, P.E.D.N.; validation, G.P. and A.A.; formal analysis, G.P. and A.A.; resources, A.V.; data curation, G.P. and P.E.D.N.; writing, A.A. and G.P.; writing and editing, A.A. and G.P.; review, A.V.; supervision, G.P. All authors have read and agreed to the published version of the manuscript.

Funding: This research received no external funding.

Conflicts of Interest: The authors declare no conflict of interest. 


\section{References}

1. Carioscia, S.A.; Locke, J.W.; Boyd, L.D.; Lewis, M.J.; HalionSun, R.P.; Smith, H. Commercial Decelopment of Civilian Supersonic Aircraft; IDA Coument D-10845; IDA Science and Technology Policy Institute: Washington, DC, USA, 2019.

2. Wood, R.M. Supersonic Aerodynamics of Delta Wings; NASA Technical Paper 2771; NASA: Houston, TX, USA, 1988.

3. Elle, B.J. An Investigation at Low Speed of the Flow Near the Apex of Thin Delta Wing with Sharp Leading Edges; Reports and Memoranda 3176; Aeronautical Research Council: London, UK, 1958.

4. Visbal, M.R. Onset of vortex breakdown above a pitching delta wing. AIAA J. 1994, 32, 1568-1575. [CrossRef]

5. Ekaterinaris, J.A.; Schiff, L.B. Numerical simulation of incidence and sweeep effects on delta wing vortex breakdown. J. Aircr. 1994, 31, 1043-1049. [CrossRef]

6. Gursul, I. Review of unsteady vortex flow over delta wings. J. Aircr. 2005, 42, 299-319. [CrossRef]

7. Taylor, G.; Gursul, I. Buffeting flows over a low sweep delta wing. AIAA J. 2004, 42. [CrossRef]

8. Nelson, R.C.; Pelletier, A. The unsteady aerodynamics of slender wings and aircraft undergoing large amplitude maneuvers. Prog. Aerosp. Sci. 2003, 39, 185-248. [CrossRef]

9. Sun, Y.; Smith, H.; Chen, H. Conceptual Design of Low-Boom Low-Drag Supersonic Transports; American Institute of Aeronautics and Astronautics: Reston, VA, USA, 2020.

10. Aerion Supersonic. 2017. Available online: https://www.aerionsupersonic.com (accessed on 8 August 2021).

11. Spike Aerospace. 2021 Available online: https://www.spikeaerospace.com/spike-images/ (accessed on 8 August 2021).

12. Boom Airliner. 2021. Available online: https://boomsupersonic.com/airliner (accessed on 8 August 2021).

13. Yoshida, K. Supersonic drag reduction technology in the scaled supersonic experimental aeroplane project by JAXA. Prog. Aerosp. Sci. 2009, 45, 124-146. [CrossRef]

14. Supersonic Project Review. NASA. 2017. Available online: https://ntrs.nasa.gov/archive/nasa/casi.ntrs.nasa.gov/20170007758. pdf (accessed on 8 August 2021).

15. Aronstein, D.C.; Schueler, K.L. Two Supersonic Business Aircraft Conceptual Designs, With and Without Sonic Boom Constraint. J. Aircraft 2005, 42, 775-786. [CrossRef]

16. Banerjee, T. Design Guidelines for Supersonic Aircrafts in Civil Aviation. Int. J. Aviat. Aeronaut. Aerosp. 2019, 6. [CrossRef]

17. Sun, Y.; Smith, H. Design and operational assessment of a low-boom low-drag supersonic business jet. Proc. Inst. Mechan. Eng. Part G J. Aerosp. Eng. 2021. [CrossRef]

18. Sun, Y.; Smith, H. Low-Boom Low-Drag Solutions through the Evaluation of Different Supersonic Business Jet Concepts. Aeronaut. J. 2019, 124, 76-95. [CrossRef]

19. Quirino, M.U.; Calvo, M.; Munjulury, R.C.; Abdalla, A.M. Analysis of the Influence of the External Configuration on the Wave Drag of Supersonic Business Jets. In Proceedings of the 31st Congress of the International Council of the Aeronautical Sciences, Belo Horizonte, Brazil, 9-14 September 2018.

20. Ghaffari, F.G.; Luckring, J.M.; Thomas, J.L.; Bates, B.; Biedron, R. Multiblock Navier-Stokes solutions about the F/A-18 wing-LEX-fuselage configuration. J. Aircr. 1993, 30, 293-303. [CrossRef]

21. Luckring, J.M. The discovery and prediction of vortex flow aerodynamics. Aeronaut. J. 2019, 123, 729-386. [CrossRef]

22. Breitsamer, C. Unsteady flow phenomena associated with leading edge vortices. Progress Aerosp. Sci. 2008, 44, 48-65. [CrossRef]

23. Cummings, R.M.; Shutte, A. Detached-Eddy simulation of the vortical flow field about the VFE-2 delta wing. Aerosp. Sci. Andf Technol. 2013, 24, 66-76. [CrossRef]

24. Jian, L.; Kunyu, L.; Haisheng, S.; Yong, H.; Zhitao, L.; Zhixiang, X. Dynamic response of vortes breakdown flows to a pitching double-delta wing. Aerosp. Sci. Technol. 2018, 72, 564-577.

25. Zhou, B.Y.; Garger, N.R. Hybrid RANS/LES simulation of vortex breakdown over a Delta Wing. In Proceedings of the Computational Fluid Dynamics Conference, Dallas, TX, USA, 17-21 June 2019.

26. Lamar, J.E.; Frink, N.T. Aerodynamic Features of Designed Strake-Wing Configurations. J. Aircrft 1982, 19. [CrossRef]

27. Katz, J.; Plotkin, A. Low-Speed Aerodynamics, 2nd ed.; Cambridge Aerospace Series; Cambridge University Press: New York, NY, USA, 2001; ISBN 978-0-521-66552-0.

28. Leibovich, S. The Structure of Vortex Breakdown. Annu. Rev. Fluid Mech. 1978, 10, 221-246. [CrossRef]

29. Delrey, J.M. Aspects of vortex breakdown. Prog. Aerosp. Sci. 1994, 30, 1-59. [CrossRef]

30. Gortz, S.; Rizzi, A.; Munukka, K. Computational Study of Vortex Breakdown over Swept Delta Wings; American Institute of Aeronautics and Astronautics: Norfolk, VA, USA, 1999. [CrossRef] 